\title{
The correlation between dietary fat quality indices and lipid profile with Atherogenic index of plasma in obese and non-obese volunteers: a cross-sectional descriptive- analytic case-control study
}

\author{
Maryam Sadat Moussavi Javardi ${ }^{1}$, Zahra Madani ${ }^{1}$, Ariyo Movahedi ${ }^{1 *}$ (D), Majid Karandish ${ }^{2 *}$ and Behnood Abbasi ${ }^{1}$
}

\begin{abstract}
Background and aim: Abnormalities in lipid metabolism are commonly observed in patients who were obese. Alongside dyslipidemia, one of the markers in predicting the risk of cardiovascular disease is the Atherogenic Index of Plasma (AIP), which is related to dietary intake. Healthy fat quality indices might affect on AIP. The purpose of this study is to find the possible relationship between dietary fat quality, and AIP and comparison of these indices among obese and non-obese volunteers.

Methods: This study was a cross-sectional descriptive-analytic case-control study with 157 normal and overweight and obese volunteers ( $n=71$ normal, Age: $38.90 \pm 10.976$ vs $n=86$ overweight/obese, Age: $38.60 \pm 9.394$ ) in the age range of 18-65 years. Food intake was measured using FFQ, anthropometric indices (weight, height, body mass index and waist to hip ratio), body composition (visceral fat level, total body water, body fat mass), and lipid profile were measured.

Results: Based on the present results, comparable biochemical parameters including TC $(P=0.580), \mathrm{TG}(P=0.362)$, LDL $(P=0.687)$ and HDL $(P=0.151)$ among overweight/obese volunteers as compared to normal ones were noticed. Effects of dietary fat quality, including Atherogenicity (Al) and Thrombogenicity (TI) hypo/hypercholesterolemic ratio $(\mathrm{h} / \mathrm{H})$, the Cholesterol-Saturated Fat Index (CSI) showed significantly higher Al $(P=0.012)$ in the overweight/obese group as compared to the normal group. Whereas, $\mathrm{h} / \mathrm{H}(P=0.034)$ and $\omega-6 / \omega-3$ ratio $(P=0.004)$ were significantly higher in normal-weight volunteers. There was a positive correlation between AI, TI, CSI, SFA, MUFA, PUFA and $\omega-6 / \omega-3$ ratio with AIP and negative correlation between $\mathrm{h} / \mathrm{H}$ with AIP in both groups. Despite the significances of these correlations no strong relation was observed by doing multiple regression among normal and overweight/obese groups $\left(R^{2}=0.210, R^{2}=0.387\right)$.

(Continued on next page)
\end{abstract}

\footnotetext{
* Correspondence: amm35@mail.aub.edu; mkarandish@yahoo.com

The authors declare that this article, is original research, has not been previously published and has not been submitted for publication elsewhere while under consideration.

'Department of Nutrition, Science and Research Branch, Islamic Azad University, Tehran, Iran

${ }^{2}$ Nutrition and Metabolic Diseases Research Center, Ahvaz Jundishapur University of Medical Sciences, Ahvaz, Iran
}

(c) The Author(s). 2020 Open Access This article is licensed under a Creative Commons Attribution 4.0 International License, which permits use, sharing, adaptation, distribution and reproduction in any medium or format, as long as you give appropriate credit to the original author(s) and the source, provide a link to the Creative Commons licence, and indicate if changes were made. The images or other third party material in this article are included in the article's Creative Commons licence, unless indicated otherwise in a credit line to the material. If material is not included in the article's Creative Commons licence and your intended use is not permitted by statutory regulation or exceeds the permitted use, you will need to obtain permission directly from the copyright holder. To view a copy of this licence, visit http://creativecommons.org/licenses/by/4.0/ The Creative Commons Public Domain Dedication waiver (http://creativecommons.org/publicdomain/zero/1.0/) applies to the data made available in this article, unless otherwise stated in a credit line to the data. 
(Continued from previous page)

Conclusions: In summary, the present work proposes a direct relationship between dietary fat quality, increased BMI, and lipid abnormalities with AIP. Nevertheless, further large-scale studies are required to sustain a clear conclusion in this wish.

Keywords: Fat quality, Atherogenic index of plasma, Lipid profile, Obesity, Overweight, Atherogenicity, Thrombogenicity, Cholesterol-saturated fat index

\section{Background}

Nowadays, non-communicable diseases (NCDs) are the most important worldwide health issue. Among NCDs obesity and hyperlipidemia are two main metabolic disorders that increase the risk of developing cardiovascular disease [1]. Obesity is classified as a category of chronic diseases $[2,3]$ and it is recognized to be an inflammatory state with increased adipose tissue and reduced levels of adiponectin, which limits its ability to suppress inflammatory processes and perpetuates the inflammatory condition [4-6]. Also, perivascular adipose tissue seems to impair local inflammation and endothelial function, particularly in obese people. Obesity due to increased intravascular inflammation and interstitial arterial thickness and decreased arterial lumen diameter reduces vascular elasticity, which eventually leads to hypertension [7]. Arterial stiffness increases systolic blood pressure (SBP) while reducing diastolic blood pressure (DBP). These consequences along with elevated pulse pressure raise the strain on the left ventricle, leading to increased risk of myocardial infarction and other coronary heart diseases (CHD) [8-10]. The global worldwide rate of CVD, which is a consequence of pandemic obesity, is expected to reach 23.6 million by 2030 [11]. Granting to the latest data published by the World Health Organization in 2018 , a rapidly increasing rate of obesity was seen worldwide, and, more than 2 billion adults aged 18 years and older were overweight. Of these, over 650 million adults were obese (WHO, 2018), and the United States at the forefront, because approximately 35\% of men and $40 \%$ of obese women are defined as having a body mass index $(\mathrm{BMI})>30 \mathrm{~kg} / \mathrm{m}^{2}[12,13]$.

On the other hand, abnormalities in lipid metabolism were noted commonly in patients who were obese. Substantial indicated that high BMI is directly or indirectly linked to high total cholesterol (TC), low-density lipoprotein cholesterol (LDL-C), and triglycerides (TG) and an inverse relationship with high-density lipoprotein cholesterol (HDL-C). Strong scientific evidence indicates that there is a solid association between BMI and lipoprotein levels, in particular, high levels of LDL-C and also a low level of HDL-C, which was proposed as a potential risk factor for CVD in obese people [14]. Therefore the LDL-C/HDL-C ratio is often calculated to estimate cardiovascular risk [15]. A more sensitive and specific index of cardiovascular risk than total cholesterol as a TC/HDL ratio, which higher than 5.5 indicates the moderate atherogenic risk [16]. Alongside dyslipidemia, one of the strongest markers in predicting the risk of CVD is the atherogenic index of plasma (AIP). Atherogenic index of plasma (AIP) is a novel index [17], which has been used to measure blood lipid levels and is usually used as an optimal indicator of dyslipidemia and associated disorders like cardiovascular diseases [18-20].

The number of nutrients and intake of their type, along with the calorie imbalance are the most important factors in weight gain and obesity. It has shown that not only each of the macronutrients such as fat, carbohydrates, and protein has different effects on weight changes [21], but also it has shown that the type and quality of the foods have different effects [22]. For instance, during the last decades, previous studies proposed some indices of dietary fat quality, including the atherogenicity index (AI) and thrombogenicity index (TI), and the ratio between hypo -hypercholesterolemic fatty acids $(\mathrm{h} / \mathrm{H})$ in the diet which might have effects on CVD and other NCD Risks [23, 24]. In 1996, Mitchell et al. have proposed another index of dietary fat quality which named Cholesterol-Saturated Fat Index (CSI) [25] and a few years later, in 2002, Simopoulos et al., proposed the importance of the ratio of omega-6/omega-3 essential fatty acids [26].

Despite having all these indices, no studies have investigated the quality of fat intake, and their possible association with AIP changes. Hence, this study aimed to find out the possible relationship between these dietary factors and AIP and compare it among overweight/obese and non-obese volunteers.

\section{Methods}

\section{Sample collection and preparation}

This study was a cross-sectional descriptive-analytic case-control study, which has been done during May 2019 till September 2019 in Tehran. Based on a sample size formula which has been calculated by using PASS 15.0 (Power Analysis and Sample Size software, NCSS LLC., Utah, USA), 128 subjects were required totally. In this study, stratified sampling method was used based on Age range, BMI, pregnancy, medical drug use. After choosing eligible samples from the main data bank, they were invited to be a volunteer in this study. Volunteers who were willing to cooperate, $\mathrm{BMI}>18.5$ and the age 
range 18-65 years, and were not pregnant or under anti dyslipidemia drugs were included in this study. The volunteers were normal weight $(18.5 \leq \mathrm{BMI}<25$ $\left.\mathrm{Kg} / \mathrm{m}^{2}\right)$ and overweight or obese $\left(\mathrm{BMI} \geq 25 \mathrm{Kg} / \mathrm{m}^{2}\right)$ adults who were randomly selected from the students and staffs of Science and Research Branch of Islamic Azad University (SRBIAU) of Tehran using stratified sampling method [27]. Overall, 71 normal weight and 86 overweight/obese volunteers were completed study missions. All the basic required information, including BMI and the latest blood test, were available in the University Electronic Health Clinic Database. Based on the registered documents in the SRBIAU Health Clinic Database, to collect the blood samples of volunteers, they have fasted overnight for $12 \mathrm{~h}$ and serum blood has been taken and centrifuged using Boeco U-320 Pathology Laboratory Centrifuge (Boeco, Hamburg, Germany). The enzymatic colorimetric methods have been used to determine the serum concentrations of the lipid profile using a Cobas C-311 analyzer (Roche, Meylan, France). Blood pressure was measured by Automatic, Noninvasive Blood Pressure Measurement BPBIO 320S (InBody BPBIO320, Eonjuro, Gangam-gu, South Korea) [28].

\section{Study implementation}

This study was approved by the ethical Iran National Committee for Ethics in Biomedical Research under code IR.IAU.SRB.REC.1396.67. All the eligible volunteers were informed about the details of the study and their rights to sign a written consent.

All the basic characteristics including age and sex were obtained through face-to-face interviews by valid questionnaires. Anthropometric indices, including weight, BMI, WHR, and body composition (visceral fat level, total body water, body fat mass) were measured using the InBody Model 270 bioelectric impedance analyzer (InBody Co. Ltd., Eonju-ro, Gangam-gu, South Korea) and height was measured using digital freestanding Stadiometer BSM-170 (InBody Co. Ltd., Eonju-ro, Gangamgu,South Korea). Dietary data were collected using a validated Iranian semi-quantitative FFQ with 147 food items [29].

\section{Fat quality indices}

To estimate of dietary fat quality indices derived from previous studies calculated using empirical equations are:

\section{Atherogenic index (Al) formula}

Indicates a correlation between the total saturated and unsaturated fatty acids. Is the sum of C12:0= Lauric acid, $\quad$ C14:0 $=$ Myristic acid, C16:0 = Palmitic acid, $\Sigma$ MUFA $=$ sum of monounsaturated fatty acids, $\sum \Phi-6=$ sum of omega- 6 polyunsaturated fatty acids, $\sum \Phi-3=$ sum of omega-3 polyunsaturated fatty acids [23].

$$
(A I)=\frac{[(C 12: 0+(4 x C 14: 0)+C 16: 0)]}{\left(\sum M U F A+\sum \varpi-6+\sum \varpi-3\right)}
$$

\section{Thrombogenic index (TI) formula}

MUFA and n-6 PUFA are less anti-atherogenic than n-3 PUFA. C14:0 = Myristic acid, C16:0 = palmitic acid, C18: $0=$ stearic acid, $\Sigma$ Sn- $6=$ total omega- 6 fatty acids, $\Sigma S n-$ $3=$ total omega- 3 fatty acids, and $\Sigma$ MUFA = sum of monounsaturated fatty acids [23].

$$
(\mathrm{TI})=\frac{(C 14: 0+C 16: 0+C 18: 0)}{\left[\left(0.5 \times \sum \text { MUFA }\right)+\left(0.5 \times \sum \varpi-6+\left(3 \times \sum \varpi-3\right)+\left(\sum \varpi-3 / \sum \varpi-6\right)\right]\right.}
$$

\section{Ratio of hypo and hypercholesterolemia $(\mathrm{h} / \mathrm{H})$}

C18:1 n-9 = Oleic acid, C18:2 n-6 = Linoleic acid, C20:4 n-6 = Arachidonic acid, C18:3 n-3 = Alpha-linolenic acid, C20:5 n-3 = Eicosapentaenoic acid, C22:5 n-3 = Docosapentaenoic acid, C22:6 n-3 = Docosahexaenoic acid, C14: $0=$ Myristic acid, C16:0 = Palmitic acid [24] .

$$
(\mathrm{h} / \mathrm{H})=\frac{(C 18: 1 \varpi-9+C 18: 3 \varpi-6+C 18: 3 \varpi-3+C 20: 5 \varpi-3+C 22: 6 \omega-3)}{(C 14: 0+C 16: 0)}
$$

\section{Cholesterol/saturated fat index (CSI)}

The Cholesterol-Saturated Fat Index (CSI) has potential as a dietary self-monitoring tool and enables patients to monitor their progress toward a cholesterol-lowering [25].

$$
(\mathrm{CSI}=) \frac{\text { Cholesterol }}{\text { Saturated fat }}
$$

\section{Atherogenic index of plasma (AIP) formula}

To evaluate the logarithm of the ratio of plasma concentration of triglycerides to HDL-C [17].

$$
A I P=\log \left[\frac{(T G)}{(H D L-C)}\right]
$$

\section{Statistical analysis}

Kolmogorov-Smirnov test as well as D'Agostino-Pearson omnibus test was used to find out the normality of the tested variables [30]. The Student's t-test was used to compare the mean of quantitative (for parametric distributions) and Mann-Whitney U test (for nonparametric distributions) was used to compare the median of outcomes between the two groups. The correlation model was used to compare the main variables of the study in case of a need for control over the main variables of the study. Also, a multiple regression test was used to predict the effects of variables on AIP. IBM SPSS Statistics for Windows version 25 (IBM Corp., Armonk, N.Y., 
USA) was used for all analyses, a $p$-value of 0.05 or less was considered to be significant with a confidence interval of $95 \%$.

\section{Results}

In the present study, the relationship between dietary fat quality indices with an AIP in overweight/obese and non-obese volunteers, with a mean age of $38.73 \pm 9.65$ years in both groups were evaluated. One hundred eighty adults, 90 overweight/obese, and 90 normal weight were enrolled based on inclusion and exclusion criteria. Of these, 23 subjects were excluded because of incomplete questionnaires (more than half of the items were not completed) and some had over/under-reporting FFQ. Finally, the study was done on 71 normal weight and 86 overweight and obese volunteers.

As shown in Table 1, all anthropometric indices except height were significantly higher among the overweight and obese group $(P<0.001)$. Moreover fat mass was significantly higher in the overweight/obese group as compared to the normal ones $(P<0.001)$. Both bone mass and total body water showed comparable differences. Biochemical results showed no significant difference for TC $(P=0.580)$, TG $(P=0.362)$, LDL $(P=$
$0.687)$, and HDL $(P=0.151)$ and significant difference for AIP $(P=0.014)$, between overweight/obese subjects and normal subjects. SBP and DBP were observed significantly higher in the overweight/obese group as compared to the normal group $(P<0.001)$. Also, a comparable pulse rate was found in the overweight/ obese group $(P=0.327)$.

According to the findings of Table 2, the results showed that AI $(P=0.012)$ was significantly higher in the overweight/obese group, whereas, $\mathrm{h} / \mathrm{H}(P=0.034)$ and $\omega-6 / \omega-3$ ratio $(P=0.004)$ were higher significantly in normal weight subject than overweight/obese subjects.

Comparable differences were found for SFAs, including Loric $(P=0.715)$, Palmitic $(P=0.875)$, Stearic $(P=$ $0.062)$, and Myristic $(P=0.325)$ acids, total trans $(P=$ $0.481)$, Cholesterol $(P=0.250)$ and MUFA $(P=0.207)$ among the overweight/obese group. The same result was observed for PUFA as well $(P=0.920)$.

As illustrated in Table 3, there was a positive correlation between BMI, AI, TI, CSI, SFA, MUFA, PUFA, and $\omega-6 / \omega-3$ ratio with AIP and negative correlation between $\mathrm{h} / \mathrm{H}$ with AIP in both groups. Significant correlations were observed between $\mathrm{BMI}(P=0.045, R=0.408)$,

Table 1 Descriptive characteristics of study participant

\begin{tabular}{|c|c|c|c|c|c|c|c|c|c|}
\hline & \multicolumn{4}{|c|}{ Normal weight (71) } & \multicolumn{4}{|c|}{ Overweight/Obese (86) } & \multirow[t]{2}{*}{$P$-Value } \\
\hline & Mean $\pm S D$ & Median & Mode & Range & $M e a n \pm S D$ & Median & Mode & Range & \\
\hline Sex $(M / F)$ & $80.3 \% / 19.7 \%$ & - & - & - & $81.6 \% / 18.4 \%$ & - & - & - & 0.731 \\
\hline Age (year) ${ }^{a}$ & $38.90 \pm 10.976$ & 39 & 30 & $18-40$ & $38.60 \pm 9.394$ & 38 & 28 & $19-47$ & 0.854 \\
\hline \multicolumn{10}{|l|}{ Anthropometric characteristics } \\
\hline Weight (Kg) ${ }^{a}$ & $73.45 \pm 10.66$ & 74.1 & 69.0 & $47-85$ & $90.05 \pm 13.22$ & 88.4 & 86.5 & $65-110$ & $0.0001^{* *}$ \\
\hline Height $(\mathrm{Cm})^{a}$ & $172.54 \pm 7.58$ & 171 & 174.5 & $157-188$ & $172.20 \pm 8.33$ & 169.5 & 173 & 156-182 & 0.789 \\
\hline $\mathrm{BMI}\left(\mathrm{Kg} / \mathrm{m}^{2}\right)^{\mathrm{a}}$ & $24.57 \pm 2.32$ & 23.2 & 22.8 & $19.2-25$ & $30.28 \pm 3.16$ & 31.3 & 30.08 & $25.4-36.6$ & $0.0001^{* *}$ \\
\hline $\mathrm{WHR}(\mathrm{Cm})^{\mathrm{b}}$ & $0.90 \pm 0.04$ & 0.87 & 0.89 & $0.83-0.92$ & $0.95 \pm 0.06$ & 0.99 & 0.98 & $0.92-1.03$ & $0.0001^{* *}$ \\
\hline Skeletal Muscle Mass $(\mathrm{Kg})^{\text {a }}$ & $33.07 \pm 3.12$ & 34.01 & 32.78 & $28.23-37.41$ & $30.93 \pm 4.86$ & 29.32 & 31.17 & $24.02-39.81$ & $0.0001^{* *}$ \\
\hline Fat $\operatorname{Mass}(\mathrm{Kg})^{a}$ & $26.74 \pm 5.06$ & 26.12 & 27.31 & $20.23-33.18$ & $37.54 \pm 4.94$ & 35.33 & 36.46 & $32.23-42.93$ & $0.0001^{* *}$ \\
\hline Bone Mass $(\mathrm{Kg})^{\text {a }}$ & $4.03 \pm 0.79$ & 4.13 & 4.27 & $3.03-4.97$ & $4.22 \pm 0.66$ & 4.32 & 4.37 & $3.43-5.07$ & 0.821 \\
\hline Total Body Water & $42.79 \pm 8.17$ & 43.90 & 41.03 & $31.23-53.45$ & $40.51 \pm 7.97$ & 41.88 & 40.71 & $30.36-50.14$ & 0.119 \\
\hline \multicolumn{10}{|l|}{ Biochemical parameters } \\
\hline $\mathrm{TG}(\mathrm{mg} / \mathrm{dl})^{\mathrm{b}}$ & $152.52 \pm 85.38$ & 144 & 139 & $66-237$ & $164.99 \pm 84.67$ & 159 & 151 & $82-263$ & 0.362 \\
\hline $\mathrm{TC}(\mathrm{mg} / \mathrm{dl})^{\mathrm{a}}$ & $172.17 \pm 35.30$ & 169 & 166 & $130-208$ & $175.06 \pm 29.90$ & 177 & 179 & $143-207$ & 0.580 \\
\hline $\operatorname{LDL}(\mathrm{mg} / \mathrm{dl})^{\mathrm{a}}$ & $98.44 \pm 29.71$ & 96 & 99 & $65-128$ & $100.22 \pm 25.75$ & 101 & 102 & $73-132$ & 0.687 \\
\hline $\mathrm{HDL}(\mathrm{mg} / \mathrm{dl})^{\mathrm{a}}$ & $44.51 \pm 8.41$ & 46 & 45 & $35-54$ & $42.40 \pm 9.67$ & 42 & 39 & $30-50$ & 0.151 \\
\hline AIP & $0.170 \pm 0.07$ & 0.161 & 0.166 & $0.16-0.18$ & $0.214 \pm 0.111$ & 0.221 & 0.232 & $0.115-0.326$ & $0.014^{*}$ \\
\hline \multicolumn{10}{|l|}{ Blood pressure, mean $\pm S D$} \\
\hline $\mathrm{SBP}(\mathrm{mmHg})^{\mathrm{a}}$ & $121.17 \pm 13.03$ & 125 & 115 & $105-135$ & $131.02 \pm 15.18$ & 140 & 135 & $115-150$ & $0.0001^{* *}$ \\
\hline $\mathrm{DBP}(\mathrm{mmHg})^{\text {a }}$ & $76.90 \pm 11.13$ & 75 & 80 & $65-90$ & $84.21 \pm 11.43$ & 90 & 85 & $75-10$ & $0.0001^{* *}$ \\
\hline Pulse (bpm) ${ }^{a}$ & $84.55 \pm 13.20$ & 83 & 82 & 70-99 & $86.63 \pm 13.19$ & 85 & 83 & $73-102$ & 0.327 \\
\hline
\end{tabular}

${ }^{a}$ Variables were compared using $\mathrm{t}$ independent test; ${ }^{\mathrm{b}}$ variables were compared using Mann-Whitney $U$ test. Percentages are compared using Chi-square. ${ }^{*}$ Stands for $P<0.05$. ${ }^{*}$ Stands for $P<0.01$. Comparison between in two groups of normal and overweight or obese; $P<0.05$ was considered to be significant 
AI $(P=0.014, R=0.859), \mathrm{h} / \mathrm{H}(P=0.033, R=-0.596)$ and SFA $(P=0.043, R=0.602)$ with AIP in overweight/obese group and were significant for the AI $(P=0.031, R=0.701)$ and $\mathrm{h} / \mathrm{H}(P=0.023, R=-0.710)$ in normal group. Despite this significance, multiple regression between these variables with AIP showed a weak relationship among the normal group $\left(R^{2}=\right.$ 0.210 ) and comparable one among the overweight/ obese group $\left(R^{2}=0.387\right)$.

As Table 4 presents, a significant correlation was observed between lipid profile and AIP in normal weight and overweight/obese groups. The positive correlation was significant between TG, TC, LDL, TC/HDL, LDL/HDL with AIP except for HDL that negative correlation was significant in both groups $\left(P<0.05, R^{2}=0.889, R^{2}=0.878\right.$, normal and overweight/obese group respectively).

\section{Discussion}

As the present study showed, comparable lipid profile was seen among overweight/obese subjects which this finding was supported with former studies as well [3133]. Based on the present knowledge depends on fat quality intake in obese and non-obese, chronic diseases such as hypertension and CVD could be prevented [34]. In the present study, participants with higher BMI had greater body fat percentage as well as AIP which was in line with the previous studies. Although it has shown that body fat distribution is associated with cardiometabolic risk factors [35], a recent study has shown that BMI by itself has a superior correlation with cardiovascular disease risk as compared to body fat [36]. Moreover, there is a positive correlation between BMI and lipid abnormalities, including increased TC, LDL cholesterol, and TG, which directly affect AIP as one of the

Table 2 The Comparison of fat quality intake in two groups of normal and overweight or obese

\begin{tabular}{|c|c|c|c|c|c|c|c|c|c|}
\hline \multirow[t]{2}{*}{ Variable } & \multicolumn{4}{|c|}{ Normal weight $(n=71)$} & \multicolumn{4}{|c|}{ Overweight/Obese $(n=86)$} & \multirow{2}{*}{$\begin{array}{l}P- \\
\text { Value }\end{array}$} \\
\hline & Mean \pm SD & Median & Mode & Range & Mean \pm SD & Median & Mode & Range & \\
\hline$\overline{\mathrm{Al}^{\mathrm{a}}}$ & $228.19 \pm 28.32$ & 226.3 & 203.04 & $197.02-260.21$ & $461.48 \pm 52.81$ & 456.93 & 469.12 & $408.08-519.01$ & $0.012^{*}$ \\
\hline $\mathrm{Tl}^{\mathrm{a}}$ & $471.15 \pm 46.14$ & 474.64 & 456.09 & $436.78-522.66$ & $484.45 \pm 50.63$ & 474.64 & 465.96 & $431.96-537.84$ & 0.841 \\
\hline $\mathrm{hH}^{\mathrm{a}}$ & $71.85 \pm 3.78$ & 69.21 & 70.43 & $66.86-75.64$ & $49.94 \pm 4.13$ & 50.69 & 49.97 & $43.35-55.14$ & $0.034^{*}$ \\
\hline $\mathrm{CS}^{\mathrm{a}}$ & $30.40 \pm 0.45$ & 30.03 & 30.64 & $29.88-31.22$ & $31.00 \pm 0.93$ & 31.10 & 30.94 & $30.07-32.33$ & 0.824 \\
\hline Total fat & $90.30 \pm 35.51$ & 89.11 & 74.07 & $55.09-126.98$ & $95.52 \pm 42.73$ & 96.78 & 97.01 & $52.49-137.24$ & 0.412 \\
\hline$\Sigma S F A$ & $19.55 \pm 8.01$ & 20.03 & 18.93 & $11.04-27.68$ & $22.01 \pm 10.40$ & 21.54 & 21.82 & $11.76-32.47$ & 0.066 \\
\hline Loric acid (c12:0) & $0.40 \pm 0.27$ & 0.39 & 0.43 & $0.12-0.68$ & $0.41 \pm 0.27$ & 0.40 & 0.45 & $0.13-0.71$ & 0.715 \\
\hline Myristic acid (14:0) & $1.43 \pm 0.87$ & 1.32 & 1.50 & $0.57-2.30$ & $1.56 \pm 0.88$ & 1.62 & 2.02 & $0.67-2.48$ & 0.325 \\
\hline Palmitic acid (16:0) & $8.43 \pm 3.64$ & 8.41 & 9.93 & $4.80-12.02$ & $9.34 \pm 4.67$ & 9.35 & 8.28 & $4.72-14.01$ & 0.875 \\
\hline Stearic acid (18:0) & $4.00 \pm 1.78$ & 4.14 & 3.94 & $2.21-5.78$ & $4.42 \pm 2.41$ & 4.52 & 4.78 & $2.01-6.71$ & 0.062 \\
\hline ¿MUFA & $23.99 \pm 11.38$ & 24.41 & 22.86 & $12.04-35.18$ & $21.97 \pm 8.61$ & 22.11 & 22.29 & $13.34-30.57$ & 0.207 \\
\hline Oleic acid (18:1) & $15.55 \pm 8.43$ & 15.98 & 14.07 & $7.33-19.42$ & $13.38 \pm 6.10$ & 13.47 & 11.55 & $7.28-19.46$ & 0.812 \\
\hline Palmitoleic acid (16:1) & $0.79 \pm 0.63$ & 0.72 & 0.70 & $0.17-1.43$ & $0.69 \pm 0.43$ & 0.68 & 0.93 & $0.24-1.15$ & 0.209 \\
\hline$\sum$ PUFA & $19.25 \pm 12.20$ & 21.22 & 15.03 & $7.20-30.03$ & $22.45 \pm 12.72$ & 21.57 & 19.31 & $8.95-33.94$ & 0.920 \\
\hline Linoleic acid (18:2n6) & $1.22 \pm 1.34$ & 1.25 & 0.73 & $0.14-2.57$ & $1.45 \pm 1.24$ & 1.59 & 1.08 & $0.20-2.69$ & 0.267 \\
\hline C18.2.CLAs & $0.41 \pm 0.72$ & 0.31 & 0.36 & $0.29-1.15$ & $0.23 \pm 0.32$ & 0.28 & 0.21 & $0.09-0.58$ & 0.144 \\
\hline Linolenic acid (18:3n6) & $0.12 \pm 0.14$ & 0.09 & 0.13 & $0.03-0.30$ & $0.17 \pm 0.13$ & 0.11 & 0.16 & $0.05-0.33$ & 0.177 \\
\hline Linolenic acid (18:3n3) & $0.41 \pm 0.27$ & 0.45 & 0.38 & $0.12-0.70$ & $0.52 \pm 0.27$ & 0.49 & 0.56 & $0.24-0.79$ & 0.565 \\
\hline Dihomo-linolenic acid (20:3n6) & $0.34 \pm 1.45$ & 0.31 & 0.26 & $0.10-1.88$ & $0.42 \pm 1.23$ & 0.45 & 0.37 & $0.08-1.79$ & 0.129 \\
\hline Arachidonic acid (20:4n6) & $0.11 \pm 0.10$ & 0.09 & 0.07 & $0.01-0.23$ & $0.18 \pm 0.08$ & 0.19 & 0.16 & $0.08-0.29$ & 0.212 \\
\hline Eicosapentaenoic acid (20:5n3) EPA & $0.04 \pm 0.05$ & 0.03 & 0.02 & $0.01-0.11$ & $0.03 \pm 0.04$ & 0.02 & 0.02 & $0.01-0.08$ & 0.615 \\
\hline Docosahexaenoic acid (22:6n3) DHA & $0.13 \pm 0.12$ & 0.11 & 0.05 & $0.01-0.26$ & $0.12 \pm 0.11$ & 0.10 & 0.08 & $0.01-0.25$ & 0.779 \\
\hline$\omega-6 / \omega-3$ ratio & $4.27 \pm 0.29$ & 4.25 & 4.50 & $3.98-4.59$ & $4.60 \pm 0.27$ & 4.61 & 4.52 & $4.32-4.89$ & $0.004^{* *}$ \\
\hline Cholesterol & $224.36 \pm 112.73$ & 228.65 & 201.12 & $110.14-332.38$ & $250.89 \pm 174.34$ & 254.08 & 247.36 & $87.12-413.97$ & 0.250 \\
\hline Total trans & $4.39 \pm 10.81$ & 3.21 & 3.89 & $3.13-15.29$ & $5.58 \pm 10.27$ & 3.98 & 4.27 & $3.51-10.09$ & 0.481 \\
\hline
\end{tabular}

${ }^{a}$ Variables were compared using $\mathrm{t}$ independent test, rest of the variables were compared using Mann-Whitney $\mathrm{U}$ test. ${ }^{*}$ Stands for $P<0.05$. ${ }^{* *}$ Stands for $P<0.01$. Abbreviation: Al Atherogenicity index; $T$ I Thrombogenicity index; $H / H$ Shypocholesterolemic/ $\Sigma$ Hypercholesterolemic ratio; CSI Cholesterol-Saturated Fat Index; $\omega$ - $6 /$ $\omega-3 \Sigma$ of Omega 6 series/ $\Sigma$ of Omega 3 series; SFAs saturated fatty acids; MUFAs monounsaturated fatty acids; PUFAs polyunsaturated fatty acids; $\omega 6$ omega 6 fatty acid (Linoleic acid); $\omega 3$ omega 3 fatty acid (Linolenic acid); $P<0.05$ was considered to be significant 
Table 3 The Correlation coefficient between BMI, dietary fat quality indices with AIP in normal weight and overweight or obese groups

\begin{tabular}{|c|c|c|c|c|c|c|}
\hline \multirow[t]{2}{*}{ Variable } & \multicolumn{3}{|c|}{ Normal weight $(n=71)$} & \multicolumn{3}{|c|}{ Overweight/Obese $(n=86)$} \\
\hline & $\bar{R}$ & $P$ value & $R^{2}$ & $\mathbf{R}$ & $P$ value & $R^{2}$ \\
\hline $\mathrm{BMI}$ & 0.193 & 0.106 & 0.210 & 0.408 & $0.045^{*}$ & 0.387 \\
\hline $\mathrm{Al}$ & 0.701 & $0.031^{*}$ & & 0.859 & $0.014^{*}$ & \\
\hline $\mathrm{TI}$ & 0.080 & 0.505 & & 0.095 & 0.381 & \\
\hline CSI & 0.085 & 0.481 & & 0.024 & 0.117 & \\
\hline $\mathrm{hH}$ & -0.710 & $0.023^{*}$ & & -0.596 & $0.033^{*}$ & \\
\hline$\sum$ SFA & 0.050 & 0.925 & & 0.602 & $0.043^{*}$ & \\
\hline ¿MUFA & 0.041 & 0.416 & & 0.015 & 0.403 & \\
\hline$\sum$ PUFA & 0.005 & 0.960 & & 0.098 & 0.581 & \\
\hline$\omega-6 / \omega-3$ ratio & 0.179 & 0.135 & & 0.087 & 0.425 & \\
\hline
\end{tabular}

* Stands for $P<0.05$. R: Pearson's correlation coefficient, Abbreviation: $A$ I Atherogenicity index; $\mathrm{Tl}$ Thrombogenicity index; $h / H \sum$ Hypocholesterolemic/ $\Sigma$ Hypercholesterolemic ratio; CSI Cholesterol-Saturated Fat Index; $\omega-6 / \omega-3=\Sigma$ of Omega 6 series/ $\Sigma$ of Omega 3 series; SFAs saturated fatty acids; MUFAs monounsaturated fatty acids; PUFAs polyunsaturated fatty acids; $\omega 6$ omega 6 fatty acid (Linoleic acid); $\omega 3$ omega 3 fatty acid (Linolenic acid). Tests were anylysed using Pearson's correlation and multiple regression test

most important risk factors for cardiovascular disease $[37,38]$. In the present study, a positive correlation between AI, TI, SFA, MUFA, PUFA, and CSI with AIP and inverse association between $\mathrm{h} / \mathrm{H}$ and AIP were noticed. These findings were similar to previous studies [39, 40]. Besides, likewise former findings all lipid profile and AIP showed a significantly positive correlation, while a significant negative correlation was found between HDL and AIP in both groups [41, 42]. Dietary fatty acids, determine the risk and protection of chronic diseases due to the chain length, number, and position of the double bonds as well as their shape (cis or trans) [43-45]. Therefore, fat quality intake can directly or indirectly have a profound effect on blood pressure and atherosclerosis $[46,47]$. The main dietary fat risk factors for

Table 4 The Correlation coefficient between lipid profile and AIP in normal weight and overweight/obese groups

\begin{tabular}{|c|c|c|c|c|c|c|}
\hline \multirow[t]{2}{*}{ Variable } & \multicolumn{3}{|c|}{ Normal weight $(n=71)$} & \multicolumn{3}{|c|}{ Overweight/Obese $(n=86)$} \\
\hline & $\bar{R}$ & $P$ value & $\mathrm{R}^{2}$ & $\overline{\mathrm{R}}$ & $P$ value & $\mathbf{R}^{2}$ \\
\hline$\overline{\mathrm{TG}}$ & $0.909^{* *}$ & 0.0001 & 0.889 & $0.919^{* *}$ & 0.0001 & 0.878 \\
\hline $\mathrm{TC}$ & $0.481^{* *}$ & 0.0001 & & $0.302^{* *}$ & 0.004 & \\
\hline LDL & $0.318^{* *}$ & 0.007 & & $0.494^{* *}$ & 0.008 & \\
\hline $\mathrm{HDL}$ & $-0.632^{* *}$ & 0.0001 & & $-0.708^{* *}$ & 0.0001 & \\
\hline $\mathrm{TC} / \mathrm{HDL}$ & $0.774^{* *}$ & 0.0001 & & $0.710^{* *}$ & 0.0001 & \\
\hline LDL/HDL & $0.586^{* *}$ & 0.0001 & & $0.510^{* *}$ & 0.0001 & \\
\hline
\end{tabular}

** Stands for $P<0.01$. $R$ Pearson's correlation coefficient, TG Triglyceride, TC Total Cholesterol, LDL Low-density lipoprotein Lipoprotein, HDL High-density lipoprotein Lipoprotein, TC/HDL Total Cholesterol to High Density Lipoprotein Ratio, LDL/HDL Low-density lipoprotein to High-density lipoprotein ratio. Tests were anylysed using Pearson's correlation and multiple regression test
CHD which could be modified in food daily intake are fats high in TC and SFA, whereas USFA includes USFAs with multiple n-6 series (Linoleic), n-3 (Linolenic), a double bond USFA, have benefits in human life [23]. Diet recommendations and policies, largely based on previous studies, have shown that reducing SFA intake can prevent chronic diseases [48]. Evidence suggests that increasing the SFA diet, most importantly Lauric, Myristic, Stearic and Palmitate acid, increases LDL lipoprotein, and eventually being a serious risk factor for CHD $[49,50]$. AI and TI are two other indicators that indicate the potential for stimulating platelet aggregation. According to the findings of Ulbricht, atherogenic proteins bind lipids to the immune and circulatory cells, and anti-atherogenic prevent plaque accumulation and reduce levels of fatty acid steroids, cholesterol, and phospholipids, prevent the development of micro and macro CHD and TI indicate a tendency to form clots in the blood vessels [23]. Foods with low levels of AI and TI (less SFA) have a greater potential for protection against coronary artery disease. Furthermore, the lipid profile associated with high trans fatty acids and palmitic acid and low consumption of linoleic acid has been associated with an increased risk of CVD [51]. Although, there is evidence that higher consumption of MUFA (consists of oleic acid) improves risk factors for CVD. The study showed that there was an inverse association between USFA intake and the risk of CVD, a meta-analysis of long term studies (more than 6 months) comparing the consumption of high MUFA diets to low MUFA diets found that high MUFA diets were associated with lower fat mass, and lower systolic and diastolic blood pressure [52]. In this regard, the major types of PUFA include $₫$ 6 and $\omega-3$ that some prospective cohort studies have shown that PUFA increases the risk of cardiovascular outcomes [53]. Although, prospective studies and randomized controlled trials provide strong evidence that replacing dietary SFA with USFA, both MUFA and PUFA, benefit cardiovascular health [50]. Another $\mathrm{h} / \mathrm{H}$ as another indicator Ratio is an important additional index to determine the effect of individual fatty acids on cholesterol metabolism [24]. In terms of the nutritional value, a greater $\mathrm{h} / \mathrm{H}$ ratio is directly proportional to a high PUFA content, which is considered more beneficial for human health. The low CSI index indicates a decrease in SFA and cholesterol and ultimately a decrease in atherogenicity. CSI may be used to compare different foods and recipes and to quickly and easily evaluate daily intake [25]. All of the above corresponds to our findings. The present study failed to find significant differences between normal and overweight/obese subjects in terms of the type of fatty acid intake. This failure might be due to either close gap of BMI between these studied subject groups, or similarly of the collected subjects in other 
variables like education, economic status, and so on. It might be possible to face significant results if only the obese subjects were included in the present study.

Many researchers believe that a ratio of $₫-6 / \varpi-3$ in the human diet should not exceed 0.5 [54]. The benefits of $\omega 3$ PUFAs for humans are associated with the synthesis of eicosanoids, such as leukotrienes, prostaglandins, and thromboxanes [55-57]. Moreover, the indices of dietary fat quality were originally developed to investigate CVD and had not been previously tested for blood biomarkers in obese and non-obese [23]. Finally, this study showed that the type of dietary fat quality and the increase in obesity and overweight caused an increase in AIP, which was significantly correlated positively with lipid profiles and the atherogenic index of food. Several crosssectional studies have shown that chronic diseases such as hypertension, dyslipidemia, and CVD are more prevalent in obese individuals [58]. According to the findings of the previous studies, there is a direct relationship between an increase in the blood atherogenic index and obesity, which ultimately predicts CVD [42]. Therefore, taking care of healthy food intake is an important factor to prevent chronic disease for all people.

\section{Study strengths and limitations}

According to the searched data bank, this study was one of the pioneer studies in this field which has focused on this area. This study, however, has a few inherent limitations. First, it was a cross-sectional study with quite moderate in size. Secondly, a wide range of ages was included in this study which might have introduced a bias for the results. Therefore to have a better conclusion larger-scale studies with different age groups could show a better and clearer view of findings. Moreover, to have a more concrete conclusion it is highly recommended to do a cohort study in the future.

\section{Conclusion}

In summary, the findings of the present study suggest a direct relationship between dietary fat quality, increased BMI, and abnormalities of lipid metabolism with AIP, which could ultimately be used as a contributing factor to CVD prediction. Even though further studies are needed to have tangible recommendations, meanwhile, taking care of dietary fat quality among people to prevent CVD would be a wise decision.

\footnotetext{
Abbreviations

AIP: Atherogenic Index of Plasma; Al: Atherogenicity Index;

TI: Thrombogenicity Index; h/H: Hypo/hypercholesterolemic ratio; CSI: Cholesterol-Saturated Fat Index; NCDs: Non communicable diseases; SBP: Systolic blood pressure; DBP: Diastolic blood pressure; CHD: Coronary heart diseases; CVD: Cardiovascular disease; BMI: Body mass index; SMM: Skeletal muscle mass; FFQ: Food frequency questionnaire; LDL-C: Lowdensity lipoprotein cholesterol; HDL-C: High-density lipoprotein cholesterol; TG: Trigliceride; TC: Total cholesterol; MUFA: Monounsaturated fatty acids;
}

PUFA: Poly-unsaturated fatty acid; SFA: Saturated Fatty acids; USFA: Unsaturated Fatty acids

\section{Acknowledgments \\ Not applicable}

\section{Authors' contributions}

MM and ZM wrote the manuscript. BA was co-advisor of the study. MK and AM were the supervisors of the study. The author(s) read and approved the final manuscript.

\section{Funding}

Not applicable

\section{Availability of data and materials}

Data supporting the results of this study are available from the Islamic Azad University's Science and Research Branch (SRBIAU) clinic, but limitations apply to the use of these data, which have been used under license for the current analysis and are therefore not accessible to the public. However, data are available from the writers with the permission of the clinic and upon fair request. It has been stated in our contract between the clinic and us that they never send us details about the participants because our data are part of a great database. Even they have their own competent statistics expert who analyzes our findings, the results were written based on his report.

\section{Ethics approval and consent to participate}

The National Committee for Ethics in Biomedical Research approved this study under code IR.IAU.SRB.REC.1396.67. The specifics of the study were told to all qualified participants and written consent was obtained.

\section{Consent for publication}

Not applicable

\section{Competing interests}

Authors have no conflict of interests.

Received: 30 May 2020 Accepted: 13 September 2020

Published online: 26 September 2020

\section{References}

1. Bennett JE, Stevens GA, Mathers CD, Bonita R, Rehm J, Kruk ME, et al. NCD countdown 2030: worldwide trends in non-communicable disease mortality and progress towards sustainable development goal target 3.4. Lancet. 2018;392:1072-88

2. WPT J. WHO recognition of the global obesity epidemic. Int J Obes. 2008;32: S120-6 [cited 2020 Aug 17] Available from: www.nature.com/ijo.

3. ASMBS. Disease of Obesity [Internet]. Am. Soc. Metab. Bariatr. Surg. 2017 [cited 2020 Aug 15]. Available from: https://asmbs.org/patients/disease-ofobesity.

4. Itoh M, Suganami T, Satoh N, Tanimoto-Koyama K, Yuan X, Tanaka M, et al. Increased adiponectin secretion by highly purified eicosapentaenoic acid in rodent models of obesity and human obese subjects. Arterioscler Thromb Vasc Biol. American Heart Association, Inc. 2007:27:1918-25.

5. Yamaguchi K, Yang L, McCall S, Huang J, Yu XX, Pandey SK, et al. Inhibiting triglyceride synthesis improves hepatic steatosis but exacerbates liver damage and fibrosis in obese mice with nonalcoholic steatohepatitis. Hepatology [Internet]. 2007:45:1366-74 [cited 2013 Jun 1] Available from: http://www.ncbi.nlm.nih.gov/pubmed/17476695

6. Lonardo A, Ballestri S, Marchesini G, Angulo P, Loria P. Nonalcoholic fatty liver disease: A precursor of the metabolic syndrome. Dig. Liver Dis. 2015;47: 181-90.

7. Owen MK, Noblet JN, Sassoon DJ, Conteh AM, Goodwill AG, Tune JD. Perivascular adipose tissue and coronary vascular disease. Arterioscler Thromb Vasc Biol. 2014:34:1643-9.

8. Franklin SS. Arterial stiffness and hypertension: A two-way street? Hypertension. 2005:45:349-51.

9. Neeland IJ, Poirier P, Després JP. Cardiovascular and metabolic heterogeneity of obesity: clinical challenges and implications for management. Circulation Lippincott Williams and Wilkins. 2018;137:1391-406. 
10. Laurent S, Cockcroft J, Van Bortel L, Boutouyrie P, Giannattasio C, Hayoz D, et al. Expert consensus document on arterial stiffness: Methodological issues and clinical applications. Eur. Heart J. 2006:2588-605.

11. Mozaffarian D, Benjamin EJ, Go AS, Arnett DK, Blaha MJ, Cushman M, et al. Heart disease and stroke statistics-2015 update : a report from the American Heart Association. Circulation. Lippincott Williams and Wilkins. 2015;131:e29-39.

12. Abdelaal M, le Roux CW, Docherty NG. Morbidity and mortality associated with obesity. Ann Transl Med [Internet]. AME Publications. 2017;5:161 [cited 2019 Jan 1] Available from: http://www.ncbi.nlm.nih.gov/pubmed/28480197.

13. Arroyo-Johnson C, Mincey KD. Obesity epidemiology worldwide. Gastroenterol Clin N Am. 2016:45:571-9.

14. Hussain A, Ali I, Kaleem WA, Yasmeen F. Correlation between body mass index and lipid profile in patients with type 2 diabetes attending a tertiary care hospital in Peshawar. Pakistan J Med Sci Professional Medical Publications. 2019;35:591-7.

15. Niroumand S, Khajedaluee M, Khadem-Rezaiyan M, Abrishami M, Juya M, Khodaee $\mathrm{G}$, et al. Atherogenic Index of Plasma (AIP): A marker of cardiovascular disease. Med J Islam Repub Iran. Tehran University of Medical Sciences. 2015;29:627-35.

16. Millán J, Pintó X, Muñoz A, Zúñiga M, Rubiés-Prat J, Pallardo LF, et al. Lipoprotein ratios: physiological significance and clinical usefulness in cardiovascular prevention. Vasc Health Risk Manag. 2009;5:757-65 Available from: http://www.ncbi.nlm.nih.gov/pubmed/19774217.

17. Dobiášová M, Frohlich J. The plasma parameter log (TG/HDL-C) as an atherogenic index: correlation with lipoprotein particle size and esterification rate inapob-lipoprotein-depleted plasma (FERHDL). Clin Biochem. 2001;34:583-8.

18. Cai G, Shi G, Xue S, Lu W. The atherogenic index of plasma is a strong and independent predictor for coronary artery disease in the Chinese Han population. Med (United States). 2017;96.

19. Yang SH, Du Y, Li XL, Zhang Y, Li S, Xu RX, et al. Triglyceride to high-density lipoprotein cholesterol ratio and cardiovascular events in diabetics with coronary artery disease. Am J Med Sci. 2017;354:117-24.

20. Bora K, Pathak M, Borah P, Hussain Ml, Das D. Association of the Apolipoprotein A-I gene polymorphisms with cardiovascular disease risk factors and atherogenic indices in patients from Assam. Northeast India Balk J Med Genet. 2017;20:59-69.

21. Austin GL, Ogden LG, Hill JO. Trends in carbohydrate, fat, and protein intakes and association with energy intake in normal-weight, overweight, and obese individuals: 1971-2006. Am J Clin Nutr [Internet]. 2011:93:836-43 Available from: https://academic.oup.com/ajcn/article/93/4/836/4597739.

22. Moussavi N, Gavino V, Receveur O. Could the quality of dietary fat, and not just its quantity, be related to risk of obesity? Obesity (silver spring) [Internet]. 2008; 16:7-15 Available from: http://www.ncbi.nlm.nih.gov/pubmed/18223605.

23. Ulbricht TLVLV, Southgate DATAT. Coronary heart disease: seven dietary factors. Lancet Elsevier. 1991;338:985-92.

24. Santos-Silva J, Bessa RJB, Santos-Silva F. Effect of genotype, feeding system and slaughter weight on the quality of light lambs. II. Fatty acid composition of meat. Livest prod Sci. Elsevier. 2002;77:187-94.

25. Mitchell DT, Korslund MK, Brewer BK, Novascone MA. Development and validation of the cholesterol-saturated fat index (CSI) scorecard: a dietary self-monitoring tool. J Am Diet Assoc. 1996;96:132-6.

26. Simopoulos AP. The importance of the ratio of omega-6/omega-3 essential fatty acids. Biomed Pharmacother Elsevier Masson. 2002;56:365-79.

27. Shi F. Study on a Stratified Sampling Investigation Method for Resident Travel and the Sampling Rate. Discret Dyn Nat Soc [Internet]. 2015;2015:1-7. Available from: http://www.hindawi.com/journals/ddns/2015/496179/.

28. Kollias A, Stambolliu E, Kyriakoulis KG, Papadatos SS, Stergiou GS. Validation of the single-cuff oscillometric blood pressure monitor InBody BPBIO320 for public use according to the 2010 European Society of Hypertension International Protocol. Blood Press Monit. 2019;24:30-2 Available from: http://journals.lww.com/00126097-201902000-00006.

29. Mirmiran P, Hosseini Esfahani F, Mehrabi Y, Hedayati M, Azizi F, Esfahani FH, et al. Reliability and relative validity of an FFQ for nutrients in the Tehran lipid and glucose study. Public Health Nutr [Internet]. 2010;13:654 Available from: http://www.ncbi.nlm.nih.gov/pubmed/19807937.

30. D'Agostino RB, Belanger A, D'Agostino RB. A Suggestion for Using Powerful and Informative Tests of Normality. Am Stat [Internet]. 1990;44:316 Available from: https://www.jstor.org/stable/2684359? origin=crossref.

31. Eslami O, Shahraki M, Shahraki T. Obesity indices in relation to lipid abnormalities among Medical University students in Zahedan, South-East of Iran. Int J Prev Med. 2019:10:15 Available from: http://www.ncbi.nIm.nih.gov/ pubmed/30820302.
32. Amini S, Shirali S, Jafarirad S, Ehsani H, Mohseni H, Bargard M. Are lipid profile, body mass index, waist circumference, and blood pressure of depressed elderly patients different from healthy subjects? Int J Prev Med [Internet]. 2019;10:185 Available from: http://www.ijpvmjournal.net/text. asp?2019/10/1/185/268750.

33. Cui R, Qi Z, Zhou L, Li Z, Li Q, Zhang J. Evaluation of serum lipid profile, body mass index, and waistline in Chinese patients with type 2 diabetes mellitus. Clin Interv Aging. 2016;11:445-52 Available from: http://www.ncbi. nlm.nih.gov/pubmed/27143868.

34. Zhu Y, Bo Y, Liu Y. Dietary total fat, fatty acids intake, and risk of cardiovascular disease: a dose-response meta-analysis of cohort studies. Lipids Health Dis. 2019;18:91 Available from: https://lipidworld. biomedcentral.com/articles/10.1186/s12944-019-1035-2.

35. Elffers TW, de Mutsert R, Lamb HJ, de Roos A, Willems van Dijk K, Rosendaal $\mathrm{FR}$, et al. Body fat distribution, in particular visceral fat, is associated with cardiometabolic risk factors in obese women. Plos One. 2017;12:e0185403 Available from: http://www.ncbi.nlm.nih.gov/pubmed/28957363.

36. Kammar-García A, Hernández-Hernández ME, López-Moreno P, Ortíz-Bueno AM, Martínez-Montaño M de L. Relation of body composition indexes to cardiovascular disease risk factors in young adults. Semergen [Internet]. Ediciones Doyma, S.L.; 2019 [cited 2020 Aug 21];45:147-55. Available from: http://www.elsevier.es/es-revista-medicina-familia-semergen-40-articulorelation-body-composition-indexes-cardiovascular-S1138359318303186.

37. Ezeukwu AO, Agwubike EO. Anthropometric measures of adiposity as correlates of atherogenic index of plasma in non-obese sedentary Nigerian males. Libyan J Med Co-Action Publishing. 2014;9.

38. Upadhyay RK. Emerging risk biomarkers in cardiovascular diseases and disorders. J Lipids Hindawi Limited. 2015;2015:1-50.

39. Hamułka J, Głąbska D, Guzek D, Białkowska A, Sulich A. Intake of saturated fatty Acids affects Atherogenic blood properties in young, Caucasian, overweight women even without influencing blood cholesterol. Int J environ res public health [Internet]. 2018;15. Available from. http://www. ncbi.nlm.nih.gov/pubmed/30424516.

40. Nugraheni R, Adnan ZA, Nuhriawangsa AMP. The correlation between dietary fats intake with total cholesterol and triglycerides levels in patients with coronary heart disease. AIP Conf Proc. 2019;2120.

41. Wu T-T, Gao Y, Zheng Y-Y, Ma Y-T, Xie X. Atherogenic index of plasma (AIP): a novel predictive indicator for the coronary artery disease in postmenopausal women. Lipids Health Dis. 2018;17:197 Available from: http://www.ncbi.nlm.nih.gov/pubmed/30134981.

42. Bo MS, Cheah WL, Lwin S, Moe Nwe T, Win TT, Aung M. Understanding the relationship between Atherogenic index of plasma and cardiovascular disease risk factors among staff of an University in Malaysia. J Nutr Metab. 2018;7027624 Hindawi limited; 2018 Available from: http://www.ncbi.nlm. nih.gov/pubmed/30116641.

43. Hadj Ahmed S, Kharroubi W, Kaoubaa N, Zarrouk A, Batbout F, Gamra H, et al. Correlation of trans fatty acids with the severity of coronary artery disease lesions. Lipids Health Dis. 2018;17:52 Available from: http://www. ncbi.nlm.nih.gov/pubmed/29544473.

44. Joris PJ, Mensink RP. Role of cis-monounsaturated fatty Acids in the prevention of coronary heart disease. Curr Atheroscler Rep. 2016;18:38 Available from: http://www.ncbi.nlm.nih.gov/pubmed/27221500.

45. Iqbal MP. Trans fatty acids - a risk factor for cardiovascular disease. Pakistan J med Sci [Internet]. 2014;30:194-7. Available from: http://www.ncbi.nlm.nih. gov/pubmed/24639860.

46. Lawes CM, Vander HS, Rodgers A. International Society of Hypertension. Global burden of blood-pressure-related disease, 2001. Lancet. 2008;371: 1513-8.

47. Anil S, Charlton KE, Tapsell LC, Probst Y, Ndanuko R, Batterham MJ. Identification of dietary patterns associated with blood pressure in a sample of overweight Australian adults. J Hum Hypertens. 2016;30: 672-8.

48. Te Morenga L, Montez JM. Health effects of saturated and trans-fatty acid intake in children and adolescents: systematic review and meta-analysis. PLoS One. 2017;12:e0186672 Available from: http://www.ncbi.nlm.nih.gov/ pubmed/29149184.

49. Mensink RP. Effects of saturated fatty acids on serum lipids and lipoproteins: a systematic review and regression analysis. World Heal Organ. 2016:1-63.

50. Briggs M, Petersen K, Kris-Etherton P. Saturated Fatty Acids and Cardiovascular Disease: Replacements for Saturated Fat to Reduce Cardiovascular Risk. Healthcare. MDPI AG. 2017;5:29. 
51. Virtanen JK, Mursu J, Tuomainen T-P, Voutilainen S. Dietary fatty Acids and risk of coronary heart disease in men. Arterioscler Thromb Vasc Biol. 2014; 34:2679-87.

52. Gillingham LG, Harris-Janz S, Jones PJH. Dietary monounsaturated fatty acids are protective against metabolic syndrome and cardiovascular disease risk factors. Lipids. 2011. p. 209-28.

53. Praagman J, Beulens JWJ, Alssema M, Zock PL, Wanders AJ, Sluijs I, et al. The association between dietary saturated fatty acids and ischemic heart disease depends on the type and source of fatty acid in the European Prospective Investigation into Cancer and Nutrition-Netherlands cohort. Am J Clin Nutr Am Soc Nutr. 2016;103:356-65.

54. Sheppard KW, Cheatham CL. Omega-6/omega-3 fatty acid intake of children and older adults in the U.S.: dietary intake in comparison to current dietary recommendations and the healthy eating index. Lipids Health Dis [Internet]. 2018;17:43 Available from: http://www.ncbi.nlm.nih.gov/ pubmed/29523147.

55. Piper K, Garelnabi M. Eicosanoids: atherosclerosis and cardiometabolic health. J Clin Transl Endocrinol [Internet]. 2020;19:100216 Available from: http://www.ncbi.nlm.nih.gov/pubmed/32071878.

56. Jiang J, Li K, Wang F, Yang B, Fu Y, Zheng J, et al. Effect of marine-derived n-3 polyunsaturated fatty Acids on major eicosanoids: a systematic review and meta-analysis from 18 randomized controlled trials. PLoS One. 2016;11: e0147351 Available from: http://www.ncbi.nlm.nih.gov/pubmed/26808318.

57. Marion-Letellier R, Savoye G, Ghosh S. Polyunsaturated fatty acids and inflammation. IUBMB Life. 2015;67:659-67 Available from: http://www.ncbi. nlm.nih.gov/pubmed/26397837.

58. Akil L, Anwar AH. Relationships between obesity and cardiovascular diseases in four southern states and Colorado. J Health Care Poor Underserved Johns Hopkins University Press. 2011;22:61-72.

\section{Publisher's Note}

Springer Nature remains neutral with regard to jurisdictional claims in published maps and institutional affiliations.

Ready to submit your research? Choose BMC and benefit from:

- fast, convenient online submission

- thorough peer review by experienced researchers in your field

- rapid publication on acceptance

- support for research data, including large and complex data types

- gold Open Access which fosters wider collaboration and increased citations

- maximum visibility for your research: over $100 \mathrm{M}$ website views per year

At $\mathrm{BMC}$, research is always in progress.

Learn more biomedcentral.com/submissions 